\title{
Seismic precursors and magma ascent before the April 2011 eruption at Axial Seamount
}

\author{
R. P. Dziak ${ }^{1 \star}$, J. H. Haxel' ${ }^{1}$, D. R. Bohnenstiehl², W. W. Chadwick Jr' ${ }^{1}$ S. L. Nooner ${ }^{3}$, M. J. Fowler ${ }^{1}$, \\ H. Matsumoto ${ }^{1}$ and D. A. Butterfield ${ }^{4}$
}

\begin{abstract}
Volcanoes at spreading centres on land often exhibit seismicity and ground inflation months to years before an eruption, caused by a gradual influx of magma to the source reservoir ${ }^{1-4}$. Deflation and seismicity can occur on time scales of hours to days, and result from the injection of magma into adjacent rift zones ${ }^{5-8}$. Volcanoes at submarine rift zones, such as Axial Seamount in the northeast Pacific Ocean, have exhibited similar behaviour ${ }^{9-12}$, but a direct link between seismicity, seafloor deformation and magma intrusion has never been demonstrated. Here we present recordings from ocean-bottom hydrophones and an established array of bottom-pressure recorders that reveal patterns of both microearthquakes and seafloor deformation at Axial Seamount on the Juan de Fuca Ridge, before it erupted in April 2011. Our observations show that the rate of seismicity increased steadily during a period of several years, leading up to an intrusion and eruption of magma that began on 6 April 2011. We also detected a sudden increase in seismo-acoustic energy about $2.6 \mathrm{~h}$ before the eruption began. Our data indicate that access to real-time seismic data, projected to be available in the near future, might facilitate short-term forecasting and provide sufficient leadtime to prepare in situ instrumentation before future intrusion and eruption events.
\end{abstract}

Since late 2006, up to four ocean bottom hydrophones (OBHs) have been deployed at Axial Seamount, one within the caldera, two on the east and west caldera rims and one on the upper south rift zone (Fig. 1). The in situ hydrophones were deployed to detect microearthquake activity once it became clear the caldera was re-inflating ${ }^{13}$, but no regional earthquakes were being detected on the US Navy real-time hydrophone arrays that monitor the area and detected the 1998 eruption $^{12,14}$. The OBH array complements a ten-year effort to measure volcanic inflation within the caldera with multiyear deployments of continuously recording bottom pressure recorders ${ }^{15}$ (BPRs). These pressure data are the only documented measurements of an inflation/deflation cycle at a submarine volcano ${ }^{16}$.

Analogous volcanic centres on land typically exhibit repeated cycles of ground inflation and seismic activity. Inflation periods lasting months to years track the influx of magma and accompanying increase in pressure within the shallow crustal reservoir ${ }^{1-4}$. When this pressure is sufficient to initiate a diking event, magma is transported laterally along the rift zone and possibly erupted at the surface ${ }^{2,4-6,8}$. Individual diking events are commonly short-lived (hours to days) and marked by ground deformation and migrating seismicity associated with the opening of a hydraulic fracture. As magma leaves the reservoir, the overlying ground surface typically subsides. The timing of this deflation signal often coincides with seismic activity, but there also are examples where the earthquake swarms are delayed by several hours relative to the onset of deflation ${ }^{2,5,6}$. Similarly, surface eruptions have been reported contemporaneously or up to several hours after deflation began. In other cases, dykes do not break the surface and eruptions are absent altogether. In comparison, only two other submarine-rift-zone eruptions have been observed in situ, one with seismic and temperature sensors (2005-2006 East Pacific Rise eruption sequence) and the other with geodetic sensors (1998 Axial Seamount; refs 10-12). Deflation of the caldera during the 1998 Axial eruption started three hours after the onset of regionally recorded seismicity ${ }^{10,12}$ and, based on the timing of a lava flow that engulfed one of the in situ instruments, the onset of eruptive activity and deflation were nearly simultaneous.

The OBHs at Axial Seamount recorded steadily increasing rates of local microseismicity beneath the caldera during the five years before April 2011 (ref. 14), mirroring the increase in seismicity observed on the real-time regional hydrophones before the 1998 volcanic event ${ }^{9,17}$, and similar to long-term seismic precursors observed at subaerial-rift-zone volcanoes ${ }^{2,3,18}$. By mid-April 2010, the number of earthquake swarms, which we define to be a sequence of $>50$ events in <one day, became more frequent (one every two to three months) and the rate of earthquakes began to increase (Fig. 2), indicating pressure in the magma reservoir was increasing. The locations of the 11 largest earthquake swarms that occurred between 2006 and 2011 are focused beneath the southeast portion of Axial's caldera. Focal depths for these earthquakes are estimated to be $<1.5 \mathrm{~km}$ (ref. 14).

Unfortunately, only three OBHs were deployed during the 2010-2011 monitoring period, instead of the four typically in use and the southernmost of these instruments remains encased in a $\sim 1.5$-m-thick lava flow from the April 2011 eruption ${ }^{16,19}$. With only two OBHs it is not possible to derive unique earthquake hypocentres; however, the two surviving OBHs and two recovered BPRs provide a detailed view of the timing and temporal evolution of the magma injection event ${ }^{16}$ (Fig. 1).

The acoustic record from the OBH located on the east side of the caldera (closest to the 2011 eruptive fissures) is shown in Fig. 3. To explain the frequency components, sequence of events and the total seismo-acoustic energy, we calculated the spectrogram and root mean square (r.m.s.) amplitude of the pressure-corrected $\mathrm{OBH}$

\footnotetext{
${ }^{1}$ Cooperative Institute for Marine Resource Studies, Oregon State University/National Oceanic and Atmospheric Administration, HMSC, 2115 SE OSU Drive, Newport, Oregon 97365, USA, ${ }^{2}$ Department of Marine, Earth and Atmospheric Sciences, North Carolina State University, Campus Box 8208 , Raleigh, North Carolina 27695, USA, ${ }^{3}$ Lamont-Doherty Earth Observatory, Columbia University, Palisades, New York 10603, USA, ${ }^{4}$ Joint Institute for the Study of the Atmosphere, University of Washington/National Oceanic and Atmospheric Administration, 7600 Sand Point Way NE, Seattle, Washington 98115, USA. *e-mail: Robert.p.dziak@noaa.gov.
} 

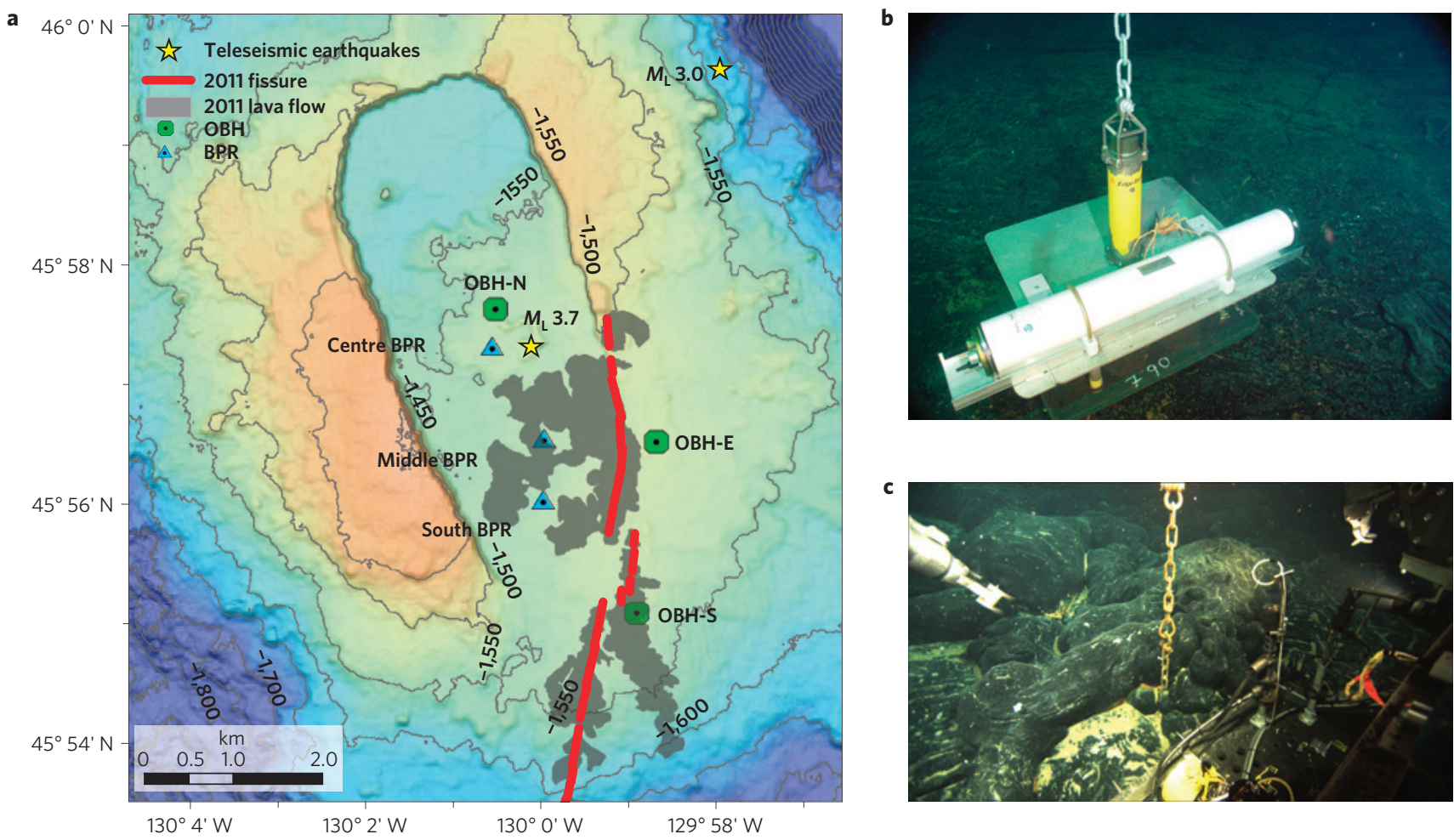

Figure 1 | Map of Axial Seamount and instrument locations. a, Bathymetric map of Axial Seamount summit caldera. Green circles show positions of three OBHs during April 2011, and blue triangles are BPRs (ref. 16). Yellow stars show locations of teleseismic events. Grey outlines show lava flows erupted in April 2011, and red lines are their source vents ${ }^{19}$. b. Picture of an OBH within the caldera in 2003. The hydrophone (white) and release (yellow) are mounted on a 30-cm-high platform; chain connects instrument to flotation. c, Picture of OBH-S overrun by a 2011 lava flow ( $1.5 \mathrm{~m}$ thick). Middle BPR was also overrun by lava.

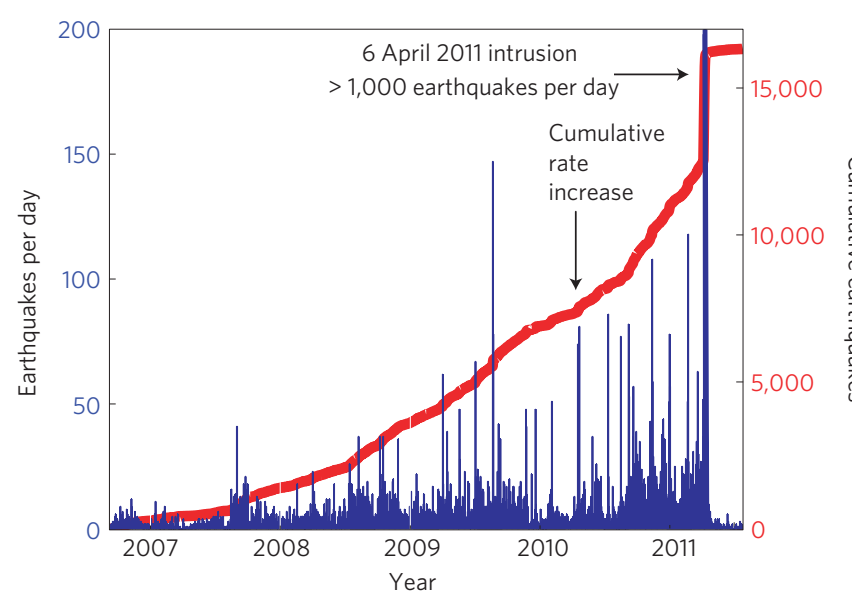

Figure 2 | Histogram of Axial Seamount earthquakes. Histogram of earthquakes per day (blue) and cumulative earthquakes (red) recorded by the OBHs at Axial Seamount. The OBHs recorded steadily increasing earthquake rates beneath the caldera during the five years before April 2011 (ref. 14). By mid-April 2010, earthquake swarms of $>50$ events per day became more frequent (every two to three months) and the cumulative number of earthquakes began to rapidly increase.

time series in one-minute windows. The onset of broadband seismic energy and an initial uptick in signal amplitude begins at 00:35 GMT on 6 April (Fig. 4). An exponential increase in r.m.s. amplitude occurs during the next $2.1 \mathrm{~h}$, tracking an increase in local earthquake and tremor activity caused by a magma dyke as it ascends through ocean crust ${ }^{20}$. Ranking the r.m.s. amplitudes based on quantile levels reveals that by 01:44 GMT, amplitudes exceed the $99.95 \%$ levels observed during the entire pre-intrusion monitoring period (Fig. 4). The r.m.s. amplitude then peaks at 02:43 GMT, exceeding the largest amplitudes observed in the years before the intrusion event by a factor of four (Fig. 4). This is followed by a steady decay in amplitude during the next ten days.

Bursts of strong volcanic (harmonic) tremor also were seen several days leading up to the 6 April event and up to two weeks afterwards. Two exceptionally strong bursts of volcanic tremor were recorded on 15 April, with signal amplitudes and durations (4-6h) significantly larger than earlier tremor intervals (Fig. 3). These signals are similar to volcanic tremor observed at subaerial systems ${ }^{21}$, with a fundamental frequency of $2.5 \mathrm{~Hz}$ and a $2.5 \mathrm{~Hz}$ overtone spacing up to $50 \mathrm{~Hz}$. The tremor signals occur during periods with very few microearthquakes and no seafloor deformation, and the strongest examples occur days after the feeder dyke should have solidified ${ }^{22}$. This suggests that the tremor does not represent the transport of lava to the surface, but rather short-term surges in the flow of magma at depths near or within the source chamber.

Even though the OBHs recorded thousands of local earthquakes at Axial Seamount during the April 2011 volcanic event, only the two largest $\left(M_{\mathrm{L}} 3.0\right.$ and 3.7) earthquakes were detected at regional and teleseismic distances by land-based stations ${ }^{23}$. The $M_{\mathrm{L}} 3.0$ event occurred at $02: 53 \mathrm{GMT}$ on 6 April and the $M_{\mathrm{L}} 3.7$ earthquake occurred at 04:11 GMT on 7 April. Incorporating the observed $\mathrm{OBH}$ arrival times and published phase data ${ }^{23}$, these events were located using a direct grid-search method that used a global one-dimensional velocity model and assumed a fixed hypocentral depth of two kilometres. The best-fitting solutions indicate that the two epicentres lie within two and one kilometres of the caldera rim, respectively, but with location uncertainties that encompass much of the volcanic edifice. The timing of these events 
a
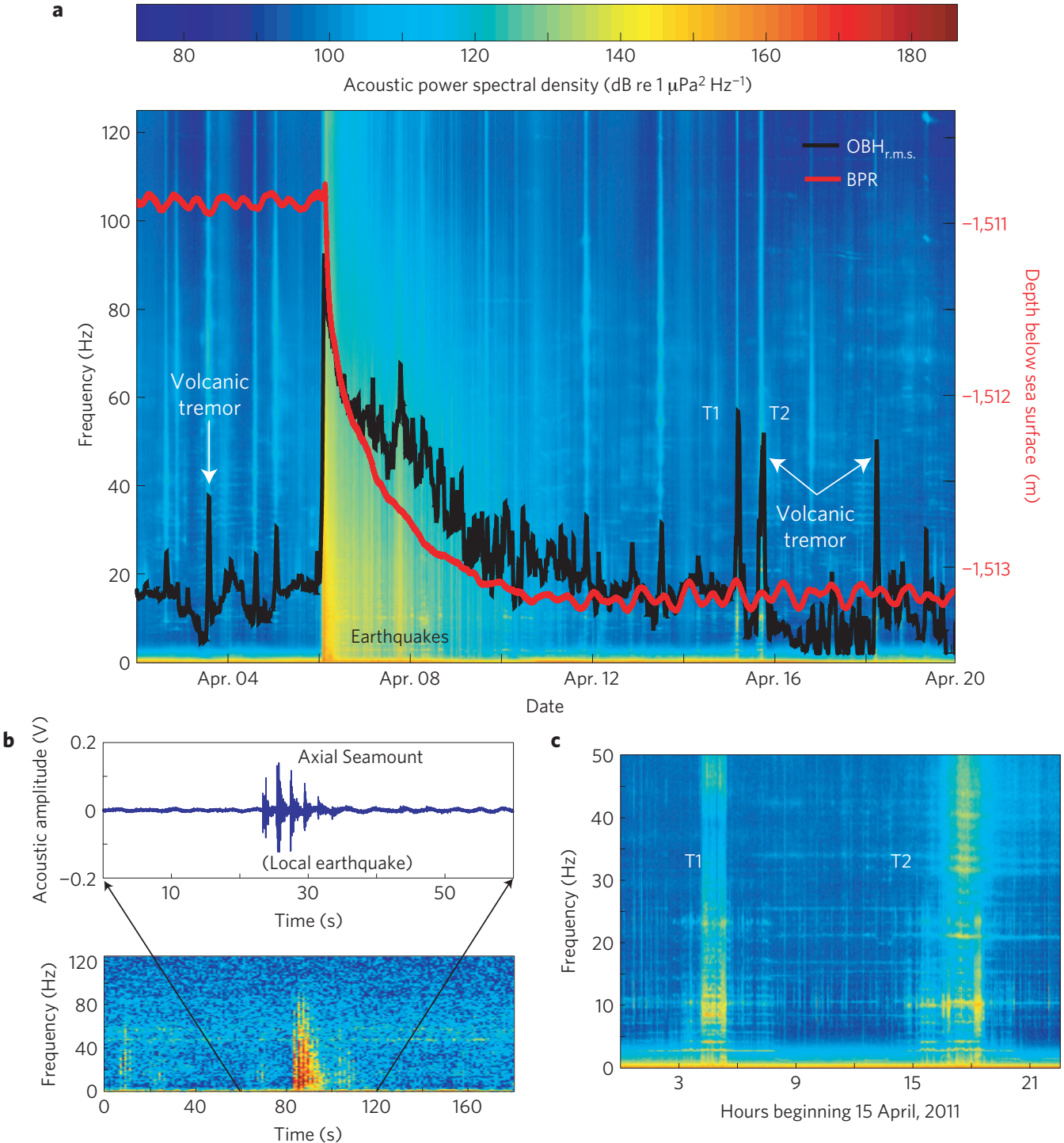

Figure 3 | Time series and spectrograms of April 2011 earthquake swarm. a, Spectrogram of OBH-E record from 2 to 20 April 2011 , overlain with r.m.s. amplitude of the $\mathrm{OBH}$ (black line) and centre caldera BPR (red line). r.m.s. values are calculated in the 0.1-125 $\mathrm{Hz}$ band from one-minute windows. Broadband energy and r.m.s. peaks mark earthquake-swarm onset. Short-duration, broadband signals are periods of strong volcanic tremor. $\mathbf{b}$, OBH record and spectrogram of typical Axial Seamount earthquake showing first arrival phase and multiple seafloor and surface reflections ${ }^{30}$. c, Spectrogram from 15 April showing detail of tremor episodes $\mathrm{T} 1$ and $\mathrm{T} 2$.

indicates the $M_{\mathrm{L}} 3.0$ event occurred during the initial magma ascent, whereas the $M_{\mathrm{L}} 3.7$ event occurred as the caldera floor subsided in response to lateral diking down-rift ${ }^{6}$.

In the BPR records ${ }^{16}$ rapid vertical movement of the caldera floor begins abruptly at 02:30 GMT, $\sim 2.0 \mathrm{~h}$ after the earthquake swarm onset and $\sim 13$ min before the maximum seismic energy release (Figs 3 and 4). On the centre BPR, the caldera uplift amounted to $\sim 7 \mathrm{~cm}$ and peaked at 03:10 $\mathrm{GMT}, \sim 27 \mathrm{~min}$ after the maximum in seismic energy. The observed BPR signal can be considered as the sum of two competing processes; uplift caused by an ascending dyke and simultaneous deflation caused by removal of magma from the subcaldera reservoir ${ }^{5,16}$. We interpret that the rapid BPR uplift became observable only when the dyke neared the surface and uplift exceeded deflation ${ }^{5,24}$. Once the dyke reached the surface and started to extend laterally down-rift, magma withdrawal from the reservoir increased and the deflation signal began to dominate the BPR records ${ }^{16}$. The delay between the onset of seismicity and the BPR uplift signal probably reflects the time required for the uplift to outpace deflation during the early stages of dyke ascent.
Temperatures recorded by the southern BPR first become elevated $\sim 4.0 \mathrm{~h}$ after the onset of deflation, before rising more abruptly $2.5 \mathrm{~h}$ later. This indicates that the dyke had breached the surface and lava was flowing within the caldera at a distance of $>1 \mathrm{~km}$ from the eruptive fissures ${ }^{16}$. However, given the modest volume of lava erupted at the summit ${ }^{19}$, the deflation signal is probably also driven by the lateral propagation of the dyke ${ }^{16}$, which moves magma from beneath the caldera into the south rift zone. The observed decrease in r.m.s. amplitude during deflation is consistent with an increasing distance between the dyke tip (and associated earthquakes) and the OBHs as the dyke extends southwards away from the caldera.

The vertical propagation speed of the dyke from the source reservoir can be estimated using the time difference between the onset of the earthquake swarm and the time the dyke nears or breaches the sea floor. Assuming the onset of BPR uplift marks the rise of the dyke into the shallow crust yields a time difference of $\sim 2.0 \mathrm{~h}$. Alternatively, assuming a seafloor eruption initiated near the time when deflation began (as was observed 


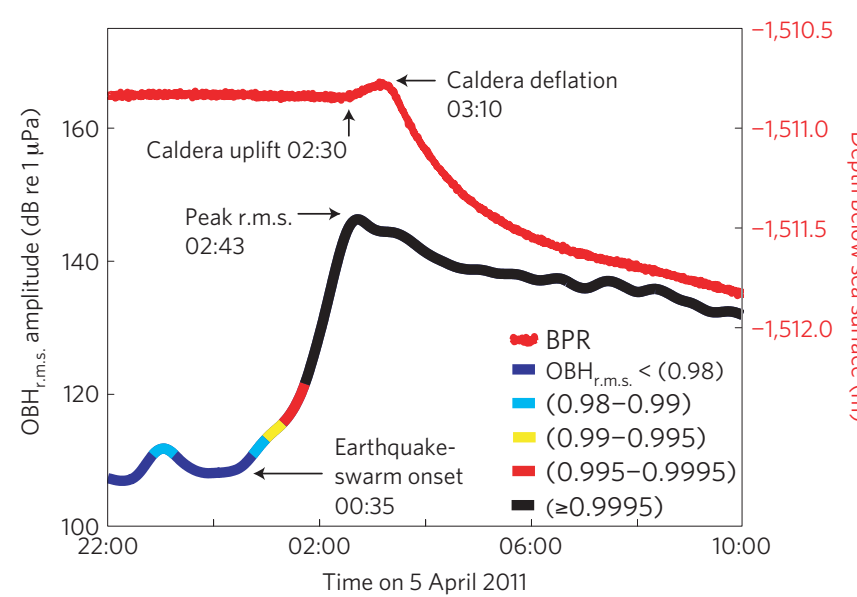

Figure 4 | Seismic and geodetic records of magma ascent. Diagram of r.m.s. amplitude from the eastern $\mathrm{OBH}$ (black curve) and centre caldera BPR (red line). Record is from 22:00 GMT on 5 April to 10:00 GMT on 6 April. r.m.s. increase at 00:35 GMT marks the earthquake-swarm onset and rise of magma. Caldera uplift of $\sim 7 \mathrm{~cm}$ begins $\sim 2.0 \mathrm{~h}$ later on both BPRs (ref. 16). r.m.s. begins to decrease $\sim 13$ min after uplift begins. Caldera deflation begins $\sim 2.6 \mathrm{~h}$ after earthquake-swarm onset and $\sim 27 \mathrm{~min}$ after peak seismic energy. Legend shows the quantile rank of r.m.s. amplitudes relative to the long-term pre-eruptive time series.

\begin{tabular}{lcl} 
Table 1 | Magma-intrusion time sequence. & \\
Event & Time & $\begin{array}{l}\boldsymbol{\Delta} \boldsymbol{t} \text { from seismic } \\
\text { onset (h) }\end{array}$ \\
\hline Seismic-swarm onset & $00: 35$ & 0 \\
Caldera uplift & $02: 30$ & 1.9 \\
Peak seismic energy & $02: 43$ & 2.1 \\
Caldera-deflation onset (centre BPR) & $03: 10$ & 2.6 \\
\hline
\end{tabular}

$\Delta t$ is time difference of events relative to the start of the earthquake swarm.

during the 1998 eruption $^{10}$ ) yields a time difference of $\sim 2.6 \mathrm{~h}$ (Table 1). The depth to the top of the Axial magma reservoir is assumed to be $\sim 1.5 \mathrm{~km}$ below the sea floor based on active source seismic imaging ${ }^{25,26}$. Thus the magma ascent velocity is constrained to be between $\sim 21$ and $16 \mathrm{~cm} \mathrm{~s}^{-1}$, consistent with magma propagation rates previously estimated at submarine $e^{11,27}$ and subaerial rift zones ${ }^{4-6,8}$. We have shown that a steady increase in seismicity rate and a rise in the frequency of earthquake swarms at Axial Seamount might be used to forecast future shallow intrusion or eruption events on timescales of years to months. Moreover, seismic and ground deformation records can be used together to track the shorter-term rise of magma from the crustal reservoir towards the sea floor. Sudden changes in the seismicity rate and seismic energy release probably mark the onset of diking and can appear several hours before magma reaches the sea floor.

Beginning in late 2013, the US regional cabled observatory will instrument the summit of Axial Seamount, providing real-time, high-bandwidth data access and adaptive sampling capabilities for a suite of multidisciplinary sensors, which will include eight ocean-bottom seismometers and three bottom-pressure/tilt recorders ${ }^{28}$. Tracking real-time seismic energy may provide an effective forecasting tool, whereby an alert is issued once short-term ground motions from local earthquakes exceed an empirically derived threshold value ${ }^{29}$. Based on nearly five years of in situ monitoring, the one-minute r.m.s. amplitudes observed during the April 2011 event can be viewed as extremely rare, with amplitudes first exceeding the $99.95 \%$ quantile within $\sim 1.25 \mathrm{~h}$ of the onset in seismic activity. Within the pre-intrusion time series, such high amplitude signals are never sustained for more than a few minutes, suggesting a shallow magma intrusion event could have been forecast soon after 01:44 GMT based on the persistence of extreme r.m.s. readings that continued to trend towards higher amplitudes (Fig. 4). Thus real-time seismic monitoring, coupled with ground-deformation sensors, could provide up to several hours of warning, allowing other seafloor instruments on the cabled array (for example, time-lapse high-definition cameras, mass spectrometer, fluid temperature, chemical and microbial samplers, current meters) to be prepared and triggered in advance of the next magmatic event at Axial Seamount.

Received 17 January 2012; accepted 4 May 2012; published online 10 June 2012

\section{References}

1. Bjornsson, A., Johnsen, G., Sigurdsson, S., Thorbergsson, G. \& Tryggvason, E. Rifting of the plate boundary in North Iceland 1975-1978. J. Geophys. Res. 84, 3029-3038 (1979)

2. Tryggvason, E. Widening of the Krafla fissure swarm during the 1975-1981 volcano-tectonic episode. Bull. Volcanol. 47, 47-69 (1984).

3. Pedersen, R., Sigmundsson, F. \& Einarsson, P. Controlling factors on earthquake swarms associated with magmatic intrusions; Constraints from Iceland. J. Volcanol. Geotherm. Res. 162, 73-80 (2007).

4. Ebinger, C. et al. Length and timescales of rift faulting and magma intrusion: The afar rifting cycle from 2005 to present. Ann. Rev. Earth Planet. Sci. 38, 439-466 (2010).

5. Einarsson, P. \& Brandsdottir, B. Seismological evidence for lateral magma intrusion during the July 1978 deflation of the Krafla Volcano in NE Iceland. J. Geophys. Res. 47, 160-165 (1980).

6. Brandsdottir, B. \& Einarsson, P. Seismic activity associated with the September 1977 deflation of the Krafla central volcano in northeastern Iceland. J. Volcanol. Geotherm. Res. 6, 197-212 (1979).

7. Tryggvason, E. Surface deformation at the Krafla Volcano, North Iceland, 1982-1992. Bull. Volcanol. 56, 98-107 (1994).

8. Belachew, M. et al. Comparison of dike intrusions in an incipient seafloor spreading segment in Afar, Ethiopia: Seismicity perspectives. J. Geophys. Res. 116, B06405 (2011).

9. Dziak, R. P. \& Fox, C. G. Long-term seismicity and ground deformation at Axial Volcano, Juan de Fuca Ridge. Geophys. Res. Lett. 26, 3641-3644 (1999).

10. Fox, C. G., Chadwick, W. W. \& Embley, R. W. Direct observation of a submarine volcanic eruption from a sea-floor instrument caught in a lava flow. Nature 412, 727-729 (2001).

11. Tolstoy, M. et al. A sea-floor spreading event captured by seismometers. Science 314, 1920-1922 (2006).

12. Dziak, R. P. \& Fox, C. G. The January 1998 earthquake swarm at Axial Volcano, Juan de Fuca Ridge: Hydroacoustic evidence of seafloor volcanic activity. Geophys. Res. Lett. 26, 3429-3432 (1999).

13. Chadwick, W. W., Nooner, S. L., Zumberge, M. A., Embley, R. W. \& Fox, C. G. Vertical deformation monitoring at Axial Seamount since its 1998 eruption using deep-sea pressure sensors. J. Volcanol. Geotherm. Res. 150, 313-327 (2006).

14. Haxel, J. H., Dziak, R. P., Matusmoto, H., Fowler, M. J. \& Chadwick, W. W. Jr A time history of microseismicity leading to volcanic eruption at Axial Volcano, Juan de Fuca Ridge. Abstract V14C-06 presented at 2011 Fall Meeting, AGU, San Francisco, California, 5-9 Dec. (2011).

15. Nooner, S. L. \& Chadwick, W. W. Volcanic inflation measured in the caldera of Axial Seamount: Implications for magma supply and future eruptions. Geochem. Geophys. Geosyst. 10, Q02002 (2009).

16. Chadwick, W. W., Nooner, S. L., Butterfield, D. A. \& Lilley, M. D. Seafloor deformation and forecasts of the April 2011 eruption of Axial Seamount Nature Geosci. http://dx.doi.org/10.1038/ngeo1464(2012).

17. Tolstoy, M., Vernon, F. L., Orcutt, J. A. \& Wyatt, F. K. Breathing of the seafloor: Tidal correlations of seismicity at Axial volcano. Geology 30, 503-506 (2002).

18. Dzurisin, D. A comprehensive approach to monitoring volcano deformation as a window on the eruption cycle. Rev. Geophys. 41, 1001 (2003).

19. Caress, D. W. et al. Repeat bathymetric surveys at 1-metre resolution of lava flows erupted at Axial Seamount in April 2011, Nature Geosci. http://dx.doi.org/10.1038/ngeo1496(2012).

20. Rubin, A. M. Dike ascent in partially molten rock. J. Geophys. Res. 103, 901-920 (1998).

21. Chouet, B. A. Long-period volcano seismicity: its source and use in eruption forecasting. Nature 380, 309-316 (1996). 
22. Delaney, P. T. \& Pollard, D. D. Solidification of basaltic magma during flow in a dike. Am. J. Sci. 282, 856-885 (1982).

23. International Seismological Centre On-line Bulletin http://www.isc.ac. uk(Internatl. Seis. Cent., 2010).

24. Mastin, L. G. \& Pollard, D. D. Surface deformatin and shallow dike intrusion processes at Inyo Craters, Long Valley California. J. Geophys. Res. 93, 13221-13235 (1988).

25. West, M., Menke, W., Tolstoy, M., Webb, S. \& Sohn, R. Magma storage beneath Axial volcano on the Juan de Fuca mid-ocean ridge. Nature 413, 833-836 (2001).

26. Carbotte, S. M. et al. Variable crustal structure along the Juan de Fuca Ridge: Influence of on-axis hotspots and absolute plate motions. Geochem. Geophys. Geosyst. 9, Q08001 (2008).

27. Dziak, R. P. et al. Rapid dike emplacement leads to eruptions and hydrothermal plume release during seafloor spreading events. Geology 35, 579-582 (2007).

28. University of Washington (Web Page about the Ocean Observatories Initiative's Regional Scale Nodes cabled observatory at Axial Seamount) http://www.ooi.washington.edu/(2012).

29. Endo, E. T. \& Murray, T. Real-time seismic amplitude measurement (RSAM): A volcano monitoring and prediction tool. Bull. Volcanol. 53, 533-545 (1991).
30. Sohn, R. A., Barclay, A. H. \& Webb, S. C. Microearthquake patterns following the 1998 eruption of Axial Volcano, Juan de Fuca Ridge: Mechanical relaxation and thermal strain. J. Geophys. Res. 109, B01101 (2004).

\section{Acknowledgements}

This work was supported by the NOAA Vents Program, the National Science Foundation (grant OCE-0725605), with support from the Pacific Marine Environmental Lab's Engineering Development Division. The authors wish to thank T-K. Lau for development of the analysis software and J. Braunmiller for discussions regarding earthquake relocation. Outstanding logistical support for this work was provided by the crews of RV Atlantis, RV Thompson and ROV Jason. PMEL contribution number 3793.

\section{Author contributions}

M.J.F. and H.M. developed, prepared and deployed the OBHs. J.H.H., D.R.B. and R.P.D. carried out hydrophone data analysis. W.W.C. and S.L.N. deployed and analysed bottom-pressure data. W.W.C. and D.A.B. were chief scientists on deployment and recovery cruises. R.P.D. wrote the paper, with editing from the other authors.

\section{Additional information}

The authors declare no competing financial interests. Reprints and permissions information is available online at www.nature.com/reprints. Correspondence and requests for materials should be addressed to R.P.D 